\title{
Perception of Political Subjectivity on the Internet: Results of the Cross-national Cluster Analysis in the USA, United Kingdom, Mexico, Sweden, Russia, China, the Republic of South Africa
}

\author{
Vladimir Dmitrievich Nechaev ${ }^{1}$, Elena Victorovna Brodovskaya ${ }^{1}$ \& Anna Yurievna Dombrovskaya ${ }^{1}$ \\ ${ }^{1}$ Moscow state University for the humanities M.A. Sholokhov, Russia \\ Correspondence: Anna Yurievna Dombrovskaya, Moscow state University for the humanities M.A. Sholokhov, \\ Verkhnyaya radishchevskaya street, 16-18, 109240, Moscow, Russia.
}

Received: November 6, 2014 Accepted: December 23, 2014 Online Published: March 16, 2015

doi:10.5539/ass.v11n7p269 URL: http://dx.doi.org/10.5539/ass.v11n7p269

\begin{abstract}
The paper presents the preliminary results of the cluster analysis devoted to the national databases research of the World Internet Project - 2012 in Russia, Sweden, China, United Kingdom, Mexico, USA and the Republic of South Africa. The purpose of cluster analysis is to classify the respondents in accordance to the characteristics of the perception of political subjectivity on the Internet. Social profiles of different user groups in selected countries can help to identify different national strategies of political activities in the "World Wide Web".
\end{abstract}

Keywords: internet communication, political activities on the Internet, cross-national cluster analysis

\section{Introduction}

The Internet has become one of the most significant tools of transforming communicative, political and social-cultural environment of the modern societies. It tends to be a centre of political empowerment of citizens all over the world.

Political recourses of the virtual space are an important research subject for a number of scientists all over the world (Anokhin, 2012; Runet.fom.ru, 2014; Brodovskaya \& Shumilova, 2013; Bubnov, Dmitrieva, \& Shapovalov, 2013; Dolgorukov, 2013; Davis, 2002; Elyakov, 2009). They reveal political effects of the Internet communication. There is a variety of sociological studies devoted to perception of political subjectivity on the Internet (Grachev, 2009; Greene, 2012), one of them is the "World Internet Project - 2012" in 50 countries (World internet project, 2014).

The purpose of this study is to identify the perception of the national political subjectivity on the Internet. Empirical objects of comparative analyses are 7 countries (China, Russia, Sweden, United Kingdom, United States, Mexico, and South Africa). The choice of these countries was determined by the desire to achieve a wide geography of a sample of countries with different systems of political, economic and social system.

\section{Method}

To collect data it was used mass pool of Russians $(\mathrm{N}=1600$, sample is representative for such areas like residence, district, gender and age) mass pool of citizens of China (1500 respondents, sample is representative for such areas like residence, district, gender and age), Sweden (2700 respondents, sample is representative for such areas like residence, district, gender and age), UK (2057 respondents, sample is representative for such areas like residence, district, gender and age), Mexico (2000 respondents, sample is representative for the type area of residence, district, gender and age), South Africa (1589 respondents, sample is representative for such areas like residence, district, gender and age), USA (1351 respondents, sample is representative for such areas like residence, district, gender and age). To verify the received data we clustered the selection of the World Internet Project in selected country with SPSS for Windows 18.0.

Procedure of allocation of clusters. The massif from the 7 countries is considered as a unit and in this "uniform" massif types of the Internet users are allocated. Further there will be an opportunity to allocate the same types of users and in the new countries.

In separate group those who "Don't use the Internet" are allocated 
Behavioral aspects of using a network are selected for cluster analysis:

- Intensity of use of the Internet in house (in a week)

- Intensity of use of the Internet at workplace (in a week)

- Intensity of use of the Internet in educational institutions (in a week)

- Intensity of use of the Internet somewhere else (in a week)

- Intensity of use of wireless mobile devices for the Internet connection

- Experience of use of wireless mobile devices for the Internet connection

- Intensity of use of e-mail

- Intensity of communication in chats

- Intensity of implementation of phone calls on the Internet

- Intensity of filling by a content of the blog

- Intensity of placement of the photos or pictures on the Internet

- Intensity of updating of the status on a social network

- Intensity of communicational activity

- Intensity of search on the Internet of some information connected with travel

- Intensity of search on the Internet of some information on new work

- Intensity of reading/searching on the Internet of some jokes, a comic content

- Intensity of search on the Internet of some information connected with health

- Intensity of participation in games on the Internet

- Intensity of shopping on the Internet

- Intensity of booking of services online

- Intensity of payment of accounts online

- Intensity of use of services of banks online

- Intensity of commission of investments into actions / bonds/funds on the Internet

- Intensity of search of definition of term/concept of the Internet

- Intensity of the information search about the concrete fact

- Intensity of the information search, connected with education

- Intensity of a distance learning

For allocation of types the Internet of users is used a method of k-means cluster. For its application it is necessary to use variables with interval or serial scales if it is possible to use these scales for determination of similarity of objects. For performance of this condition there are made some transformations of the selected variables:

- The block of questions about duration of use of the Internet in different places (houses, at work, on study, etc.) are averaged in the new variable "Intensity of Using Network". On the one hand, it allows to level the distinction caused by the main employment of respondents: someone spends at home most of his time, someone studies; someone works. On the other hand, it allows to mark out the intensity of use of the Internet.

In the block of questions about intensity of use different "the Internet parties" and about experience of the mobile Internet, version of the answer "I find it difficult to answer" on sense corresponds to version of the answer "I don't use this party".

Z-standardization is carried out.

Sample of the empirical research. Social and demographic parameters of national selections:

Great Britain

Gender distribution of respondents: men are presented to $48 \%$, women in $52 \%$ of respondents. Age differentiation of respondents looks as follows: 7,8\% - aged from 14 till 18 years; $6,9 \%$ - from 19 to 23 years; 
$35,5 \%$ - from 24 to 43 years; $17,1 \%$ - from 44 to 53 years; $12 \%$ from 54 to 63 years; $20,7 \%$ of 64 years are also more senior.

China

Gender distribution of respondents is expressed in the following differentiation: 64,1\% - men; 35,9\% - women. On an age sign respondents are presented in the following distribution: 4,4\% - aged from 14 till 18 years; $17,3 \%$ - from 19 to 23 years; $51,1 \%$ - from 24 to 43 years; $14,5 \%$ - from 44 to 53 years; $8,2 \%$ - from 54 to 63 years; $4,5 \%$ - of 64 years are also more senior.

Russia

On a gender sign respondents are differentiated as follows: $46 \%$ of men and $54 \%$ of women. Age distribution of respondents is presented in the following groups: 14,6\% - aged from 14 till 18 years; 7,3\% - from 19 to 23 years; $36,4 \%$ - from 24 to 43 years; $17,3 \%$ - from 44 to 53 years; $15,6 \%$ - from 54 to 63 years; $8,8 \%$ - of 64 years are also more senior.

\section{Sweden}

In gender distribution $50,6 \%$ of men and $49,4 \%$ of women are presented. From a position of age distribution respondents are differentiated as follows: 8,2\% - aged from 14 till 18 years; $9,2 \%$ - from 19 to 23 years; $27,6 \%$ from 24 to 43 years; $15,2 \%$ - from 44 to 53 years; $14,7 \%$ - from 54 to 63 years; $25 \%$ - of 64 years are also more senior.

\section{Mexico}

In a gender ratio $53 \%$ of men and $43 \%$ of women are presented. Age differentiation of respondents: $20,3 \%$ aged from 14 till 18 years; $17,5 \%$ - from 19 to 23 years; $38,8 \%$ - from 24 to 43 years; $12,6 \%$ - from 44 to 53 years; $6,5 \%$ - from 54 to 63 years; $4,4 \%$ - of 64 years are also more senior.

\section{Republic of South Africa}

1589 respondents entered a sample, among them $54,2 \%$ make men and $45,8 \%$ - women. Age differentiation of respondents looks as follows: $11,2 \%$ - aged from 14 till 18 years; $15,3 \%$ - from 19 to 23 years; $43,4 \%$ - from 24 to 43 years; $12,6 \%$ - from 44 to 53 years; $9,3 \%$ - from 54 to 63 years; $8,2 \%$ - of 64 years are also more senior.

\section{United States of America}

From the point of view of a gender respondents are differentiated as follows: 54,1\% - men; 45,9\% - women. Age distribution of respondents is presented in the ratio: 7,9\% - aged from 14 till 18 years; $6,1 \%$ - from 19 to 23 years; $27,6 \%$ - from 24 to 43 years; $17,5 \%$ - from 44 to 53 years; $18,7 \%$ - from 54 to 63 years; $22,1 \%$ - of 64 years are also more senior.

\section{Main Results}

Cluster analysis was carried out using the method of K-means SPSS for Windows 18.0. The results of this type of analysis are the profiles of the Internet users, shown in Table 1. Development and interpretation of the profiles was based on the papers and books of a wide range of researchers studying the trends of the Internet communication in the modern world (Freeman, 1997; Barber, 2001; Bimber, 1998; Cairncross, 1997; Castells, 2009; Coleman, 2005; Etzioni, 1993; Norris, 2001; Poster, 1997; Rheingold, 1991; Ward, Gibson, \& Lusoli, 2003; Weber, Loumakis, \& Bergman, 2003)

Table 1. Profiles of the Internet users, $\%$

\begin{tabular}{cccccccc}
\hline & UK & China & Russia & Sweden & Mexico & South Africa & USA \\
\hline "Human digital" & 14,6 & 18,1 & 5,9 & 12,8 & 3,4 & 6,3 & 23,9 \\
"Human entertaining" & 13,5 & 17,3 & 33,4 & 8,8 & 41,8 & 8,0 & 7,0 \\
"Human pragmatic" & 27,3 & 3,5 & 4,4 & 49,5 & 1,9 & 4,9 & 40,2 \\
"Human traditional" & 21,7 & 5,3 & 23,9 & 16,4 & 17,7 & 14,9 & 14,6 \\
"Human non-digital" & 22,8 & 55,7 & 32,4 & 12,5 & 35,4 & 65,9 & 14,3 \\
Total & 100 & 100 & 100 & 100 & 100 & 100 & 100 \\
\hline
\end{tabular}


Identified profiles Internet communications have different attitudes towards political opportunities of "World Wide Web". Table 1 shows the distribution of shares of the data clusters in the selected countries. The most common use of the potential of political inclusion is "Human digital" profile. There are the people whose livelihoods subordinated to all kinds of use of the Internet and all kinds of its capabilities and resources. An important characteristic of this profile is to consider the World Wide Web as a meaning of solving all the problems, including the way of expression of political subjectivity. According to Table 1, the biggest part of such profile is represented in the USA.

The explanation of this may deal with a rather long history of the Internet in this country and the fact that it contains the broad possibilities of the development of political subjectivity of citizens in a global network. The lowest percentage of the cluster is in Mexico, Russia and South Africa. In these countries there is a fairly small proportion of the population perceives the positive resources of the Internet and uses it as a space for political participation. This can be explained as the underdeveloped Internet - communication political subjectivity and political apathy of a large number of citizens.

Profile of "Human entertaining" is intensive user of the Internet, but only for recreation and leisure activities. In general, the representatives of this profile rather skeptical or indifferent to the global network and do not perceive it as a tool for business or political participation. This cluster is mostly represented in Mexico and Russia. The study found differences in the causes of the prevalence of this cluster among Russians and Mexicans. In Russia, most of these respondents do not trust the Internet content (77.8\%), and therefore prefer to use it only for relaxation and enjoyment. In Mexico, a much smaller proportion of respondents said no reliable information from the Internet (56.1\%). Thus, almost half of Mexicans in general trust the Internet content, but prefers not to use it for business purposes. There are several reasons for this fact. The most important reason is in Mexican lifestyle with its focus on fun and lack of orientation of the majority of citizens of Mexico to use the power of the Internet as a tool for economic and political participation, and lack of information on these issues.

Profile of "Human pragmatic" focused on the use of the Internet only in business and instrumental interests. People in this cluster regularly, make active use of the Internet and demonstrate a level of trust to the Internet content. Focusing its attention primarily on pragmatic reasons for using of a global network, these people allow the possibility of its use as a factor of enhancing their political subjectivity. The greatest numbers of respondents in this cluster are the citizens of Sweden and the USA.

Profile of "Human traditional" characterizes people randomly and sporadically using the Internet. They prefer traditional sources of information, do not trust the Internet content, and do not believe to the possibility of increasing political subjectivity through the Internet. Leaders in the number of members of the cluster are Russia and the United Kingdom.

Finally, "Human non-digital" is the part of the population that does not participate in Internet communications. As a rule, the reason for not using the Internet is its inaccessibility (without a computer, the high price of Internet access, lack of skills to use the Internet). The reasons for not using the Internet so-called ex-users in most cases is the lack of interest in the network and the time to use it. Most representatives of the cluster are in South Africa and China - countries in which the Internet communication began to develop quite not long ago.

To identify the relationship of the political system, the intensity and the nature of Internet communications present data benchmarking the development of telecommunication systems in selected countries and typological analysis of the characteristics of their political systems.

Figure 1 shows the results of a comparative analysis of the features of the political system and the development of Internet communications in the selected countries.

There are many indexes of development of Internet communications. The most impotent of them: The Web Index, Freedom on the Net, The United Nations E-Government Survey.

The index of development of the Internet (The Web Index) is developed in 2012 under the leadership of Timothy Berners-Li (Tim Berners-Lee) who is the founder of the concept of the World wide web. The Internet level of development is an important indicator of social development today. It is supposed that the Index can be used by the states as the tool for carrying out the analysis of problem points in their policy and implementation of monitoring of the progress in area of introduction of Internet technologies.

The index measures a level of development and influences of the Internet on society in various parameters united in three main groups.

1. Web Readiness: an assessment of a level of development and quality of communication infrastructure in the country, and also developments of institutional infrastructure and its regulatory aspects. 
2. Web Use: an assessment of level and intensity of use of the Internet in the country.

3. Impact of the Web: an assessment of social, economic and political indicators of development of the state in the context of influence of the Internet on them.

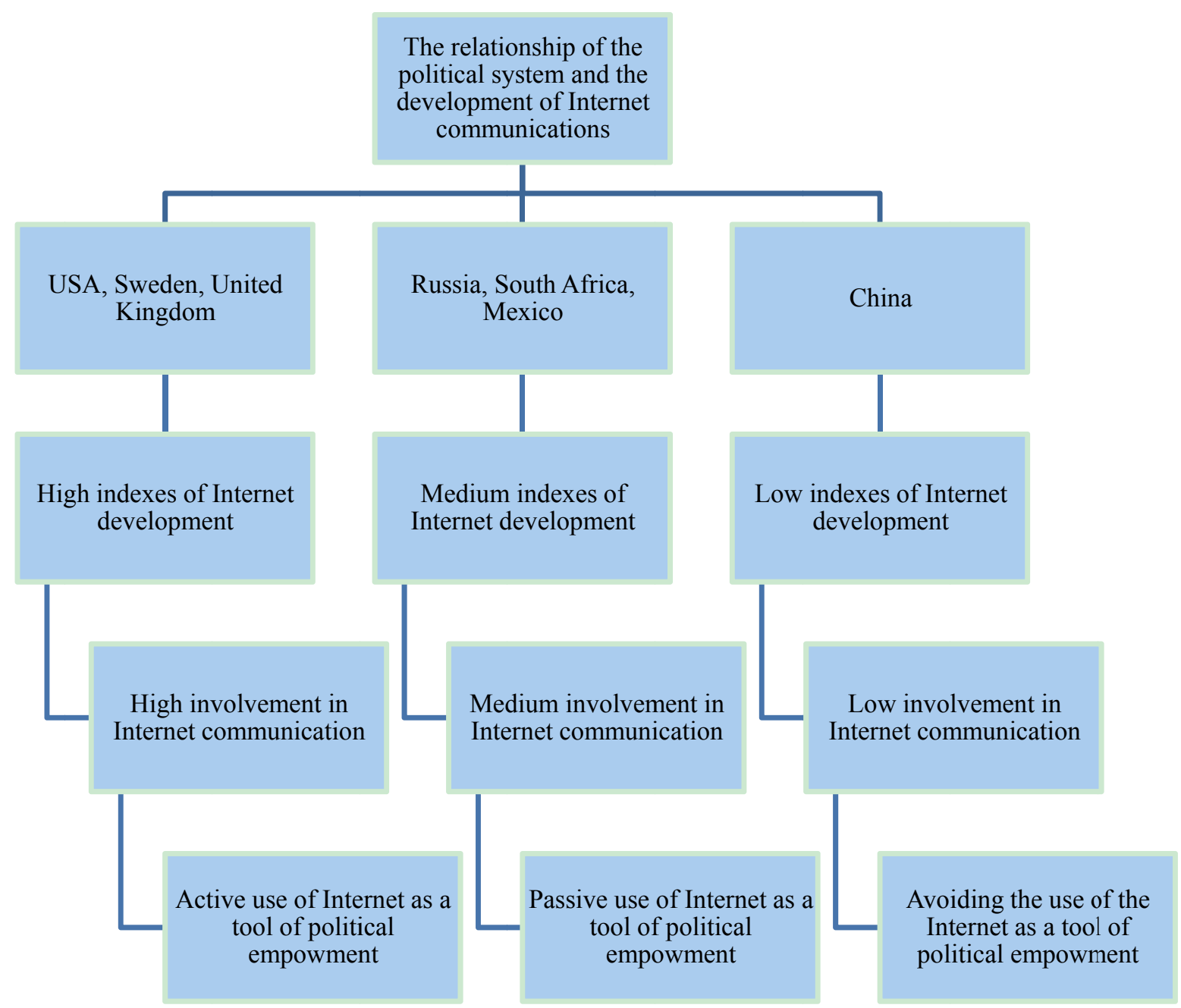

Figure 1. The results of a comparative analysis of the features of the political system and the development of Internet communications in the selected countries (USA, United Kingdom, Mexico, Sweden, Russia, China, the Republic of South Africa)

The settlement part of the Index is executed on the basis of statistical data of the international organizations, such as the United Nations, the International union of telecommunication, the World Bank, the World economic forum, Wikimedia Fund and others, and also results of the expert survey conducted in the countries which became objects of research. In the final report indicators are reduced in uniform Web Index.

Thus, there is a rating on the basis of which cross-national and cross-temporal comparison is realized.

Freedom House assesses the level of Internet freedom in countries around the world, starting in 2011 (Freedom on the Net). The study is based on the methodology of expert assessments. Information for a project collect as foreign correspondents and consultants of Freedom House. Also used data of various international organizations, government reports, reports of local and international media. The priority of the project focused on the freedom to distribute information of public significance, and protection of user rights to privacy and freedom from legal or extra-legal consequences arising from their activities on the Internet.

Conclusions about the state of Internet freedom, our professionals make on the basis of evaluation criteria such as freedom of information distribution in the Network, forms of censorship and self-censorship, legal restrictions, 
the degree of government control of the Internet and its variants, the conditions for the operation of online journalists in the country, violence against Internet activists, violation of the rights of Internet users, and so on, All countries are divided into three groups - with "free," "partly free" and "free" Internet. According to the rating of Freedom House, 0-30 points, which receives one or another country, mean free Internet, 31-60 - partly free, 61-100 points - proprietary .

The United Nations (UN) is implementing a study by The United Nations E-Government Survey: E-Government for the Future We Want" (a Rating of e-government development), which assesses the readiness and capabilities of national government structures in 193 countries in the use of information and communication technologies (ICT) for the provision of public services. All countries covered by this study, are ranked in the ranking based on the weighted index estimates for the three main components: the coverage and quality of Internet services, the level of development of ICT infrastructure and human capital. The indicator for each of the three components, in turn, consists of many parameters, including information services and web sites of public services and their accessibility for citizens, the relative number of Internet users, the number of users of fixed and mobile telephony, level of literacy, regulatory and other factors .

The majority of the specified indexes has the highest value in the countries with open political systems and the democratic modes. Data on two of these indexes are most indicative: by results of 2012 the Web Index is equal in the USA 97,31; in Sweden - 100; in Great Britain - 93,83. The Freedom on the Net index for all these countries indicates existence of the free Internet. The index of The United Nations E-Government Survey in these countries has the highest value, indicating the efficient development of e-government.

The countries with partially dug out political system and the mixed political regime have average values of the specified indexes in Russia - 47,29; in Mexico - 57,68; in South Africa - 44,49. The Freedom on the Net index for all these countries indicates existence of partially free Internet. The index of The United Nations E-Government Survey in these countries indicates the existence of problems, the formation of e-government.

In China as in the country with the closed political system and an authoritarian political regime the most indicative is Freedom on the Net index as means existence of not free Internet.

\section{Discussion}

Summarizing the analysis of the main results of the study, noted that the trend in the development of the Internet communication has a significant national conditionality. Most positive about the possibilities, including political participation via the Internet, and implement them - the citizens of the United States and China are the most pragmatic in the use of the network - the Swedes and again the Americans, the Russians and the Mexicans often use the Internet as a way of relaxation; most traditional in the choice of sources of information and communication - the British and the Russians, while ignoring the power of the Internet, and, finally, the citizens of South Africa have the lowest figures in the development of the Internet space. In general, the results show insufficient intensive use of the "World Wide Web" as a factor of political communication and the expression of political subjectivity of most citizens of almost all of the countries studied.

Thus, the revealed law, expressed in the existence of the relationship type of the political system, the type of political regime, the intensity and content of Internet communications. For such countries with open political systems and democratic political regimes, such as the USA, UK, Sweden is characterized by a combination of high performance telecommunication system development, high level of Internet penetration and the prevalence of active users globalalloc network that uses all of its resources and capabilities, as well as focused on the functional use of the capabilities of the world wide web.

Countries with a partially open political system and a mixed political regime, such as Russia, Mexico and South Africa, are characterized by a low level of development index Internet medium involvement in online communication and dominance orientation on the use of the global network as a tool of leisure and informal communication. Citizens of these countries do not implement fully the possibilities of political and economic subjectivity on the Internet, mainly for reasons of ignorance or skepticism to these resources the World Wide Web and domination installations to use the relaxation of the Internet.

Finally, for China as a country with a closed political system and the authoritarian political regime characterized by a rather low involvement in online communication (including due to existing restrictions on access to the global network), low rates of development of the Internet and virtually complete absence installation on the implementation of political subjects on the Internet.

Note that the trends in the development of Internet communication have significant national and political conditionality. These relationships are expressed in the following positions: 
- The degree of openness of the political system and the level of democratization of the political regime in the country is directly proportional to correlate with the level of development of telecommunication technologies and involvement in the Internet communications of citizens;

- The degree of openness of the political system and the level of democratization of the political regime in the country determines the character and content strategy Internet communication, in other words, the type of Internet culture in the country. In countries with open political system and democratic political regime dominated by the types of "Human digital" and "Human pragmatic", which implies a relatively high level of implementation of the political subjectivity of citizens on the Internet. In countries with partially open political system and a mixed political regime dominated by the types of "Human entertaining" and "Human traditional" that determines not very high realization of online political subjectivity of citizens. For countries with closed political regimes and authoritarian political regime is characterized by the dominance of "Human non-digital", which greatly affect the actual lack of political subjectivity in the global electronic network.

\section{Conclusions}

This research revealed types of perception of political resources of the Internet users of various countries. Further an important research task the analysis of interrelation of development of political systems and Internet communication is submitted. Hypothesis that which demands further empirical check is an assumption that a political system of the state significantly determines features of Internet communication.

For this purpose it is necessary to check a number of the provisions provided below.

1. There is an interrelation between degree of openness of political systems and level of openness of Internet communication: the open type of political system / the consolidated democracy corresponds to open character to Internet communication/lack of the institutionalized Internet communication restrictions; partially open political systems / hybrid political regimes establish control of some aspects of Internet communication; the closed political systems / authoritarian political regimes produce an institutionalization of control of Internet communication.

2. There is an interrelation between character of a political regime and level of penetration of the Internet: the open type of political system / the consolidated democracy corresponds to the high level of penetration of the Internet; partially open political systems / hybrid political regimes - to the average level of penetration of the Internet; the closed political systems / authoritarian political regimes - to the low level of penetration of the Internet.

3. The structure of consumption of Internet content isn't coherent to type of political system / a political regime and depends more on features of a co-evolution of institutional and socio-cultural factors of Internet communication (such as perception of political subjectivity users of a global network, formation of "network readiness", a level of development of communication infrastructure, degree of development of the electronic government, etc.).

4. Co-evolution communication between type of political system / character of a political regime and intensity, scale, openness of Internet communication can be mediated by specifics of national character.

5. The important factor in a certain measure predetermining structure of consumption of Internet content in the countries with various types of political systems / political regimes is the level of "network trust" and an assessment of reliability of information in a global network, i.e. can reflect a condition of legitimacy of a political regime (the level of legitimacy of the mode is higher, the share of the users who aren't limiting Internet communication with any type of Internet content is more essential; the level of legitimacy of the mode is lower, the share avoiding the political content and content connected with the pragmatic purposes is more significant). Proceeding from it, Internet communication can act as one of instruments of reproduction of the developed political order.

6. It is possible to assume that domination in structure of consumption of Internet content of information reflecting pragmatical inquiries of users is connected with a level of development of deliberativny nature of democracy. Where the modern state actively involves institutes of civil society, the democratic public, expert community in cooperation for achievement of a public consent and joint adoption of political decisions at relative openness the Internet is used mainly in the pragmatical, reducing expenses / increasing effects purposes.

7. The factor of "openness"/lack of regulation of Internet communication probably has less essential value and influence on co-evolution of political and communicative processes, than communication scale which is chosen by the user, and also his readiness to realize social, economic, political and other opportunities of the Internet. 


\section{Acknowledgements}

The study was funded by the Ministry of Education and Science of the Russian Federation in the framework of the implementation of the state task "Identifying patterns of the relationship of political systems and Internet communications" for 2014-2016. Code of the state task is 2816.

Group of authors thank Jeffrey Cole (Head of World Internet Project) and his American national research team, Grant Blank (United Kingdom), Pamela Davisson (Sweden), Jannee Elvelid (Sweden) and Liu Xin (China) for providing the database of national research trends in the development of the Internet communications.

\section{References}

Anokhin, M. (2012). Social computing in forming the "reputational capital": a synergistic effect. Proceedings of the First International scientific - practical conference "Social Computing: Fundamentals, technology development, social and humanitarian effects" (IISC-12): Collection of articles and abstracts. Moscow: Publishing House of Sholokhov Moscow State University for the humanities.

Barber, B. (2001). The uncertainty of digital politics: Democracy's uneasy relationship with information Technology. Harvard International Review, 23, 42-48.

Bimber, B. (1998). The Internet and Political Transformation: Populism, Community, and Accelerated Pluralism. Polity, 1, 112-119. http://dx.doi.org/10.2307/3235370

Brodovskaya, E. V., \& Shumilova, O. (2013). Russian users and nonusers: ratio and the main features. Monitoring of public opinion: economic and social changes, 3, 5-18.

Bubnov, A. Y. (2012). Ideology in the political segment of social networking . Proceedings of the First International scientific - practical conference "Social Computing: Fundamentals, technology development, social and humanitarian effects" (IISC-12): Collection of articles and abstracts. Moscow: Publishing House of Sholokhov Moscow State University for the humanities.

Bubnov, A. Y., Dmitrieva, O. V., \& Shapovalov, V. L. (2013). The intensity of the involvement of Russians in Internet communication. Monitoring of public opinion: economic and social changes, 3, 19-27.

Cairncross, F. (1997). The Death of Distance: How the Communications Revolution Will Change Our Lives. Boston: MA: Harvard Business School Press.

Castells, M. (2009). Communication power. Oxford: Oxford univ. press.

Coleman, S. (2005). New mediation and direct representation: reconceptualizing representation in the digital age. New Media Society, 2,177-198. http://dx.doi.org/10.1177/1461444805050745

Davis, R. (2002). Network policy: The impact of the Internet on the American political system. Actual problems of Europe. The media and democracy in the modern world. Mosow: RANINION.

Dolgorukov, A. M. (2013). E-Ethnomethodology: from "social computing" to "computable sociology". Social Computing. Scientific journal, 2, 56-68.

Elyakov, A. D. (2009). Russian society in the information dimension. Sociological researches, 7, 85-94.

Etzioni, A. (1993). The Spirit of Community: rights, responsibilities, and the communitarian agenda. New York: Crown Publishers.

Freeman, R. (1997). Democracy in the Digital Age. London.

Grachev, M. N. (2009). "E-democracy": opportunities and threats. Internet and Modern Society. Tr. XII All-Russia. Combine. conf. St. Petersburg, 27-29 October 2009. St. Petersburg: Faculty of Philology and Arts, St. Petersburg State University.

Greene, S., (2012). Twitter and protest in Russia: memes, networks and mobilization. Retrieved December 25, 2012, from http://www.newmediacenter.ru/ru/2012/05/22/

Internet audience in Russia and its regions. (2012). Retrieved February 15, 2014, from http://runet.fom.ru/

Norris, P. (2001). Digital Divide. Civic Engagement, Information Poverty, and the Internet Worldwide. Cambridge: Cambridge University Press.

Poster, M. (1997). Cyberdemocracy: Internet and the Public Sphere. New York: Routledge.

Rheingold, H. (1991). The Great Equalizer. Whole Earth Review.

Ward, S., Gibson, R., \& Lusoli, W. (2003). Online participation and mobilization in Britain: Hype, hope and 
reality. Parliamentary Affairs, 56, 652-668.

Weber, L. M., Loumakis, A., \& Bergman, J. (2003). Who participates and why? An analysis of citizens on the Internet and the mass public. Social Science Computer Review, 21, 26-42. http://dx.doi.org/10.1177/ 0894439302238969

World Internet Project annual conference. (2012). World Internet Project. Retrieved February 15, 2014, from http://www.worldinternetproject.net/\#news

\section{Copyrights}

Copyright for this article is retained by the author(s), with first publication rights granted to the journal.

This is an open-access article distributed under the terms and conditions of the Creative Commons Attribution license (http://creativecommons.org/licenses/by/3.0/). 